Portland State University

PDXScholar

8-1-2017

\title{
"So, you're not doing this right": Perception Versus Reality of Transgender Students' Experiences at Portland State
}

Charles N. Breyer

Portland State University

Follow this and additional works at: https://pdxscholar.library.pdx.edu/honorstheses

Let us know how access to this document benefits you.

\section{Recommended Citation}

Breyer, Charles N., "'So, you're not doing this right": Perception Versus Reality of Transgender Students' Experiences at Portland State" (2017). University Honors Theses. Paper 468.

https://doi.org/10.15760/honors.468

This Thesis is brought to you for free and open access. It has been accepted for inclusion in University Honors Theses by an authorized administrator of PDXScholar. Please contact us if we can make this document more accessible: pdxscholar@pdx.edu. 
"So, you're not doing this right":

Perception Versus Reality of Transgender Students' Experiences at Portland State

By

Charles N. Breyer

An undergraduate honors thesis submitted in partial fulfillment of the requirements for the degree of Bachelor of Arts in University Honors and Psychology

Thesis Adviser

Eric Mankowski, Ph.D

Portland State University 
"So, you're not doing this right":

Perception Versus Reality of Transgender Students' Experiences at Portland State Charles N. Breyer

Portland State University

Author Note

Charles N. Breyer, Department of Psychology, Portland State University.

This research was done under the instruction of Eric Mankowski and with the support of the Portland State University Honor's College.

Correspondence concerning this article should be addressed to Eric Mankowski, Department of Psychology, Portland State University, Portland, OR 97201.

Email: mankowskie@pdx.edu 


\begin{abstract}
Transgender people in the United States experience mistreatment and discrimination, as well as harassment and violence, at much higher rates than the general population. In university classrooms specifically, it is possible that less conspicuous forms of prejudice-based behavior are even more common. Though past research addresses transgender college students' perceptions of peer and faculty support (Pryor, 2015) this support cannot be adequately provided if faculty lack an accurate understanding of the issues transgender students face. In hopes of providing better support for transgender students, the present study utilizes semi-structured, one-on-one interviews with students and faculty to better understand the overlap between faculty perceptions of issues faced by transgender students in the classroom and the reality experienced by transgender students. Student and faculty ideas for addressing these issues are also presented.
\end{abstract}

Keywords: transgender, prejudice, classroom 
"So, you're not doing this right":

Perception Versus Reality of Transgender Students' Experiences at Portland State While there is no singular or agreed-upon definition of transgender (often abbreviated trans), Moran \& Sharpe (2004) approximate it as, "an umbrella term to include all persons who cross gender boundaries," (p. 413). [For a more complete definition, appropriate usage, and related terms (e.g., cisgender), see Davidson (2014), Chang \& Chung (2015), Austin (2016), and Chang, Singh \& Rossman (2017)] The Report of the 2015 U.S. Transgender Survey (James, Herman, Rankin, Keisling, Mottet, \& Anafi, 2016), the largest survey examining the experiences of transgender people in the United States, reveals that transgender people in the United States experience mistreatment and discrimination, as well as harassment and violence, at much higher rates than the general population. Nearly half of transgender persons surveyed $(46 \%)$ experienced verbal harassment in the past year due to their transgender status, while almost one in ten $(9 \%)$ was physically attacked by a stranger (James et al., 2016). Perhaps in relation to recent "bathroom bill" legislation introduced across the U.S., more than half (59\%) of the transgender individuals surveyed reported avoidance of public restrooms due to fear of confrontation (James et al., 2016). Such treatment has a significant impact on both physical and mental health: $8 \%$ of transgender respondents reported having a urinary tract infection, kidney infection, or other kidney-related problem in the past year as a result of restroom avoidance, while $40 \%$ of transgender respondents reported having attempted suicide in their lifetime (representing nearly nine times the rate of the general population, 4.6\%) (James et al., 2016). While some may reason that such treatment is the result of "ignorance", the problems do not stop with increased education: of transgender respondents who entered higher education institutions, 
nearly one fourth (24\%) reported continued verbal, physical, or sexual harassment (James et al., 2016).

In university classrooms specifically, it is possible that less conspicuous forms of prejudice-based behavior, deemed microaggressions, are even more common. Based on the experiences of persons of color, Sue et al. (2007) define microaggressions as, "brief and commonplace daily verbal, behavioral, or environmental indignities, whether intentional or unintentional, that communicate hostile, derogatory, or negative racial slights and insults toward people of color," (p. 271). Such interactions are often unconscious, and have become so pervasive that they are often overlooked entirely (Sue et al., 2007, p. 273). As the concept of microaggressions has now been applied to many marginalized groups, Nadal, Rivera, \& Corpus (2010) use this model to describe a proposed taxonomy with eight categories of microaggressions based on sexual orientation or transgender identity. These categories include use of transphobic or heterosexist language, dehumanization or objectification due to identity, and assumption of pathology or abnormality, all of which are experienced by transgender persons (Nadal, Rivera, \& Corpus, 2010).

Unfortunately, though useful, a theoretical taxonomy of microaggressions experienced by all LGBT (Lesbian, Gay, Bisexual, and Transgender) persons does not fully illuminate the specific forms of discrimination encountered by transgender individuals. For this reason, Nadal, Skolnik \& Wong (2012) identify twelve categories of microaggressions specific to the transgender experience, including the use of incorrectly gendered terminology and endorsement of gender normative and binary culture or behaviors (Nadal, Skolnik \& Wong, 2012). While in some ways, these categories align with taxonomies of microaggressions related to race and 
gender, it is important to note that transgender individuals reported unique issues such as the physical threat of violence, intrusive questions about their bodies, and denial of self-identification (Nadal, Skolnik \& Wong, 2012). Adding to this work, Chang \& Chung (2015) note that experiences of microaggressions differ between transgender individuals with different gender expressions, with some forms especially prevalent or specific to particular identities. For example, some transgender or gender-nonconforming individuals may experience microaggressions related to the use of binary gender-based pronouns and expectations of gender roles, while others may experience microaggressions related to use of the incorrect binary pronoun (Chang \& Chung, 2015, p. 224).

As educational settings play such a large part in the lives of youth and young adults, it is critical that these environments seek to work proactively to assess and combat behaviors rooted in prejudice. While youth are beginning to identify as transgender or present themselves in gender-nonconforming ways at younger ages, Austin (2016) makes the important note that, "historically...many individuals did not self-identify as [transgender or gender-nonconforming] until late adolescence or early adulthood," and are found within all levels of education (p. 227). For this reason, university environments are important targets for change. As Austin (2016) notes, consciously-inclusive education can have not only an important impact on transgender students' self-acceptance, but on the development of positive and supportive stances toward transgender people more broadly (p. 228).

Though minimal, a small amount of research on the experiences of transgender college students does exist (Garvey \& Rankin, 2015; Palkki, 2017; Pryor, 2015). However, while past research addresses transgender college students' perceptions of peer and faculty support (Pryor, 
2015) this support cannot be adequately provided if faculty lack an accurate understanding of the issues transgender students face. Furthermore, the power imbalance inherent in faculty/student relationships places the faculty perspective as an important point of intervention: faculty may not harbor intentional prejudice toward their transgender students, but may still cause harm through ignorance and prejudice-based behavior, including a failure to intervene in the harmful behaviors of students' peers. On the other hand, while transgender students have the experiential knowledge of the problems they face, students (especially of marginalized status) are generally not favored with the institutional or social power to intervene in a classroom setting.

For these reasons, the present study utilizes semi-structured, one-on-one interviews with students and faculty at Portland State University (PSU) to better understand a) faculty perceptions of issues faced by transgender students in the classroom, b) the reality experienced by transgender students in the classroom, and c) how much awareness students and faculty share of common issues that arise. The present study seeks not only to contribute new voices to existing narratives of the transgender college experience, but to illuminate gaps in faculty knowledge through which these experiences may be improved. For this reason, the present study concludes by presenting student and faculty ideas for addressing these issues.

\section{Method}

This research was reviewed and approved by the Portland State University Human Subjects Internal Review Board (IRB). As the student investigator is a member of the LGBTQ+ community, identifies as transgender, and has led workshops in the past for educators working with LGBTQ+ students, research was able to draw upon experiential knowledge and existing peer relationships. 
Data collection involved semi-structured, one-on-one interviews with students $(n=2)$ and faculty $(n=7)$ participants. To be eligible for the interview, students were required to be 18 years or older, to self-identify as transgender, and to have taken a class at PSU within the last calendar year. Since the present study focuses specifically on the experiences of self-identified transgender students, students who did not identify as transgender were excluded from participation. Interviewed faculty were required to have taught one or more courses at PSU within the last calendar year. While faculty participants were not excluded based on gender identity, none of the faculty interviewed identified themselves as transgender.

To recruit participants, a convenience sampling technique was used. The study was advertised to self-identified transgender students using the university's Queer Resource Center (QRC) Facebook page and through printed flyers of the Facebook post in the QRC office. Once contacts were made, participants were asked to refer other potential participants in a snowball sampling method. Since the study was conducted during the final term of the academic year, there was some difficulty recruiting students. Faculty participants were recruited using a list compiled by the QRC ("Supporters of the Queer Community”). Professors listed were matched with public listings on the university website, which provided email addresses that were used to solicit interest in participation. Interviews were scheduled over a period of two months from April, 2017 through June, 2017 based on the sequential order of responses to recruitment efforts.

Interviews were conducted using two lists of questions developed by the interviewer, one each for faculty and student participants. Students were asked questions about their transgender identity (e.g., "How would you describe your own gender?") and classroom experiences at PSU (e.g., "Think of a time you were treated differently based on your transgender identity in the 
classroom; can you describe this experience?"). Professors were asked questions about their general knowledge of transgender students (e.g., "To your knowledge, have you had any transgender students in your classes?") and their classroom experiences at PSU (e.g., "Do you feel as though transgender students at PSU face specific challenges when interacting with professors and other students?'). Interviews lasted between 26 and 57 minutes. Interviews were digitally audio recorded, transcribed, and analyzed for prominent themes by the author. Faculty interviews lasted an average of 42 minutes, while student interviews lasted an average of 41 minutes. Any identifying information from the interviews was removed during the transcription process, and interviewees were given the opportunity to choose a pseudonym to represent themselves in the final report. All interviews were held in private areas on the university campus (e.g. private study rooms in the library, faculty offices) chosen by the interviewees.

\section{Findings \& Discussion}

\section{Faculty Perception}

All of the faculty interviewed identified themselves as non-transgender (cisgender) allies to the LGBTQ+ community. Faculty participants discussed their own perceptions of the issues faced by transgender students in their classrooms. Faculty participants' understanding of the issues faced by trans students were at times shaped by conversations and relationships with past students, while other faculty formed their understanding through informal observation and outside sources such as academic articles and information provided by the university's Queer Resource Center (QRC).

When asked to describe the barriers faced by transgender students at PSU, all faculty participants interviewed included some form of the phrase, "ask trans students," in their answer. 
However, when indirectly prompted for the same answer through a description of their own experiences with students, faculty respondents gave examples of what they ultimately saw as the two main issues facing transgender students: inappropriate comments from classmates and improper name or pronoun usage.

Inappropriate comments from classmates. In describing their experiences working with transgender students, faculty participants gave examples of times where they needed to intervene in class discussions due to inappropriate language from other students, and times when they wish they had. Faculty participants also described the different dilemmas that arose through web-based interactions versus face-to-face classes. One professor describes the dilemma faced when dealing with the less overt nature of harmful language used in online discussion, noting:

These sort of things get subtle, you know? Like, in terms of like- how a student may have some pretty deep and dark negative feelings about these issues, but they know how to express it in a way that uh, isn't too provocative...the sort of stuff you'd see on social media.

This professor continued, noting that the same language when used in class may have more of a visible effect on students, and is therefore more difficult, as a professor, to ignore:

If it happens in a face-to-face discussion and uh, it's very clear that things are getting stressed...I will intervene and say, "Well hey, you're entitled to that opinion, but the language we're beginning to use is becoming more harmful and negative, and I don't think we need to engage in that." [Then] I will try to articulate whatever views are being expressed in the most charitable way, [but] of course, I'm more sensitive to the students who are likely to feel somehow harmed or abused. 
Improper name or pronoun usage. While none of the faculty participants mentioned instances of peer use of transgender students' improper names or pronouns, several noted that as instructors they have been active perpetrators of this issue, specifically when reading a transgender student's incorrect name as provided on the class roster. Due to the gendered implications of many names, stating a transgender student's incorrect name in front of the class serves not only to misidentify them, but to misgender them as well. One faculty participant described this as a common mistake made by professors, but also noted the larger significance that this act has for trans students, who may in some cases consider their past selves (of a different name and gender) to be literally or metaphorically "dead":

[This is] likely to cause awkward situations. You know, I've just recently learned the term deadname- where you accidentally deadname a student who's trans...I really love teaching, and [want] what's best for my students. I want them to feel comfortable, I want to honor them [laugh] and um [long pause] respecting someone's gender identity is a big part of that.

\section{Student Reality}

Both of the transgender students interviewed identified themselves as "non-binary", and are therefore referred to using the pronouns "they" and "them". Such language use aligns with observations made by Saltzburg and Davis (2010), that trans individuals may use language outside of mainstream gendered discourse, specifically "revamping" pronouns and titles to gender-neutral terms that better suit their identities (p. 88). Student participants revealed four main issues faced in university classrooms: feelings of alienation or tokenization, student/professor role-reversal, disrespect or invalidation of trans identity, and (in)action from 
professors. Students also described some of the outcomes they have witnessed as a result of these issues.

Feelings of alienation or tokenization. The students interviewed expressed feelings of being separated from other students by virtue of their transgender identity. For one interviewee, this experience of being a "minority" in the classroom provided a window through which they were better able to understand others' experiences:

[Being transgender] really gives me some perspective. Like, how alienating it can be in a classroom, um, for anyone that isn't immediately comfortable in academia, or like doesn't have um, like the same access or privileges that others do.

The students interviewed also noted the expectations they often felt from their classmates: that as the sole visible trans student, they would provide the "trans perspective" in class discussions. In one example, an interviewee described their experience in a class discussion comparing Jim Crow segregation and anti-transgender "bathroom bills":

I felt everybody in the class [laugh] just start to look at me like waiting for me to, to respond, or like to say something, or to input- like, of course I did, I basically was like, "You can't compare those that way," like that's a very different situation- but um, it becomes like, once you're outed, once you're like the person in the room who is now going to be able to, like, be identified as relevant to this, people are going to look at you, to expect something from you.

Student/professor role-reversal. The most frequently expressed theme by both of the transgender students interviewed was the feeling of role-reversal experienced when they are placed into the role of "educator" on trans issues or identity. While the interview questions did 
not ask about this specifically, it was brought up by both interviewees a number of times, and seemed to be a point of great frustration. One interviewee notes:

I think that um, [long pause] I have definitely been put in the position where I had to like educate professors. Um, on like their own, like, language choices.

Though not a responsibility they actively seek out, the same interviewee notes a sense of "duty" to step in:

Someone has to like, you know, fix it. Someone has to teach it, and then that responsibility falls onto trans students, if they're even comfortable enough to do it. The other student interviewed echoed this sentiment, noting that for the purpose of educating their professor and peers, they have at times felt it necessary to share aspects of their identity that they wouldn't otherwise:

There's been moments when I've just had to interrupt somebody and be like "Hey," basically out myself, and be like, "So, you're not doing this right," and like I'm telling you from an informed place that this is how you should do this in the future...Having to be that like student in the room who is like probably the only person who can like inform anybody about it, and having to like take on a teacher role while you're there being a student is really like [long pause] it can be really, can feel really privacy-violating. Disrespect or invalidation of trans identity. The students interviewed also described experiences of disrespectful or invalidating behavior from both classmates and professors. Both interviewees noted times in which they were not taken "seriously" due to their transgender status, as well as times in which their trans identity was treated as a joke or distraction. Through 
the stories they provided, it was clear that this experience was particularly common during introductions at the beginning of the term. One interviewee gave a recent example:

Well, we were going around doing introductions, um, and [the professor] said, "Okay, so we'll do your name, your major, what got you into this [course], and what- like, what's your favorite class that you've taken at PSU?" and someone said, "Could we also do pronouns?" and three people laughed.

The same interviewee later elaborated on why this behavior from their classmates was particularly hurtful:

People's laughter response like really gauges the fact that like they know exactly what's being asked, you know? They know what like conversation is being opened up with that, but they shut it down because they don't feel like it's worth participating in.

(In)action from professors. Another recurring theme that the students described was the effect of (in)action from professors: when teaching a class that included transgender students, professors acted in ways that were either actively harmful, or failed to address harmful behavior from themselves or students' peers. Another interviewee spoke more in depth about the rationale behind their expectations for action from professors:

I look at the professor as like the best way to stop [harmful behavior], or like the best way for that to be- the best- they set the tone for the class, right? So like, if they normalize pronoun checks, if they normalize, like, being respectful of like certain identities and not using certain words, or like um, the way that they talk about those things, they normalize that. Um, it really sets the tone for the rest of the class to- even if they make mistakes, it feels like that's an academic mistake, where [students] can learn from the professor. 
On a positive note, one interviewee noted that in the same way that professors can model harmful behavior, they can also model helpful behavior, such as taking responsibility for mistakes they make. For example, when corrected on pronoun usage by a transgender student in the class:

[One] teacher actually handled that really well, and really owned [the] responsibility, and how [they] messed up, and therefore the rest of the class messed up because of it.

Outcomes. As a result of dealing with the issues outlined above, the transgender students interviewed described several examples of negative outcomes. For example, the interviewee who earlier outlined their experience of disrespect and invalidation from peers noted the impact it had on not only their classroom experience, but their experience of an entire academic program: My own entire classroom experience is changed when somebody [does] something or says something transphobic...I went from like, being really energized about that program, and like really excited to participate and work with all these other [students], and then like, the moment three of them laughed, and then none of them [the other students in the class] stopped to be like, "Woah, that's not okay," like, I can't trust anyone in this room [laugh]. Actually, every single person in here doesn't [care]. Like, that made me so uncomfortable that I actually didn't socialize with any of my [peers]. Which one of the points of that program is to bring people together who have common interests so that they can like network and stuff.

Though they never claimed to speak for anyone but themselves, interviewees also noted the results of harmful classroom experiences on other transgender students in their classes. One 
interviewee described what they felt was a common result of the role-reversal experienced by many trans students:

Halfway through the term they'll vanish, [and when] I follow up with them later like, “Hey, where'd you go?” they weren't comfortable in the class, you know? They dropped it, they took an F, whatever. It was because they felt like the teacher wasn't able to provide, or like facilitate, a space where they could be a student, um, instead of a teacher for others.

\section{Overlap in Student and Faculty Awareness}

On the surface, actions observed by faculty participants to be issues faced by their transgender students (e.g., inappropriate language from classmates, improper name or pronoun usage) were the same as those noted by transgender student participants. However, for transgender student participants, the distress felt as a result of these actions was not due to the acts themselves, but to each action's role as a smaller piece making up their broader experience as a transgender person. While the professors were able to observe and, to a degree, understand the harm that resulted from individual acts, the insight they were lacking was the larger meaning felt by transgender students who experience similar acts on a regular basis, inside and outside of the classroom.

As noted, when asked for suggestions on ways to improve the classroom experiences of their transgender students, faculty respondents unanimously included some form of, "ask trans students," in their response. Even though faculty respondents seemed to recognize many of the basic issues that transgender students deal with (e.g., inappropriate language from classmates, improper name or pronoun usage), overall they seemed hesitant to interfere in less blatant 
instances of prejudice-based behavior without some prompting from their trans students. Several faculty respondents even went as far as to describe their experiences working with transgender students as some form of a "gradual learning process" wherein they as instructors were “well-meaning” but ultimately needed to be corrected and educated by their transgender students. Unfortunately, as the transgender students interviewed took serious issue with being put into the role of "instructor" in classroom settings, it stands to reason that the benefit provided to faculty of the experiences and insight of transgender students may result in its own unique form of harm for the students themselves.

\section{Implications for Education and Practice}

Faculty. In discussing ways to address the issues faced by transgender students, and to make their classes generally more trans-friendly, faculty participants were typically unable to come up with new ideas, but instead gave a range of examples from their own teaching practices. One interviewee noted the positive effect of an educational speakers' panel from the university's Queer Resource Center (QRC):

One time I invited a panel from the QRC, to discuss different gender and sexual identities, and that seemed to be a really good experience, and I got a lot of positive feedback [from students] about that specific incident [the panel].

Another professor mentioned a more subtle strategy of inclusion via course content:

I do try in a lot of my classes to introduce, where appropriate, content from trans authors, or about transgender issues...and I do know from student responses that it has been very eye-opening for a lot of students [and] it's giving them an opportunity to encounter some of these experiences for the first time. 
Several professors noted classroom introductions as an especially important area of intervention.

One interviewee noted that by looking ahead and allowing students to take the lead in offering their own information, there are fewer opportunities to make mistakes:

You can see on a roster that there's a male name, but it says "preferred" a different name that's usually a different gender, right? So you become sensitive to that. [I try to] kind of review the roster ahead of time, being aware of any places where you would need to be sensitive [but] creating a process where students can introduce themselves does help to avoid situations like that.

Faculty participants also noted the importance of being mindful of language more broadly, specifically when addressing students in gendered ways. One professor notes:

[I am] overall trying to use more gender-neutral language, trying to avoid statements that really lean on heteronormativity in general...and like just thinking about that sort of thing. Outside of their own experience, faculty participants were also open to suggestions. When asked about including pronoun sharing in introductions, one professor simply remarked:

You know, I haven't! And that's something that I probably should do...[sometimes] when you don't have a lot of experience with people who are different from you, it's hard to know where to begin.

Overall, faculty participants seemed to be very interested in making their classrooms more welcoming to transgender students, but often expressed that their own feelings of ignorance led them to look to transgender students to dictate what changes should happen. 
Student. In discussing ways to improve the classroom experience for other transgender students like themselves, student participants at times remembered behavior they witnessed in past courses. In one example of this, a student describes a useful activity on the first day of class:

[One professor] had us um, do name plaques with our pronouns on them so that people could like, you know, use them and it would be very regular and very obvious, and even explained to the class why it was so important to respect gender identity and pronouns. More commonly, however, student participants provided insight through descriptions of what professors failed to do in a given situation:

So that reoccurring theme that I've seen a lot of is like, professors don't normalize pronouns...they don't take the initiative- unless they like really, really care and they're really, really trying- they don't take the initiative to actually ask people [what pronouns they use].

Overall, while the student participants seemed to appreciate some of the steps taken by professors, they often expressed that some proactivity on the part of the professor would be preferred to reliance on themselves or other transgender students. These interviewees cited resources such as the Queer Resource Center and other existing formal means of anti-oppression education as good places for professors to start. As one participant stated simply, "you have the internet!"

\section{Implications for Theory and Practice}

In reflecting on the differences between faculty perceptions and student experiences, the author of the present study suggests the metaphor of an iceberg as a theoretical model. The iceberg metaphor is commonly used across disciplines to conceptualize the discrepancies 
between what is on the "surface" and the larger underlying "depth" of a particular concept or practice. When comparing the lived experiences of transgender students with faculty perceptions of these experiences, findings suggest that faculty understanding represents what is above the water, while student experiences comprise the body beneath. As noted earlier, the concrete "surface" actions observed and noted by faculty participants are experienced by transgender students. However, the larger body of the the iceberg - what transgender students report that they actually experience - is comprised of not only a more severe experience of these concrete surface actions, but also of actions that professors are unable to see, as they themselves are the perpetrators.

In classroom settings, findings suggest that while centering student voices is of utmost importance, educational institutions should not rely on students to take initiative in addressing the harmful behaviors of peers and faculty in their courses. Instead, the author of the present study would advocate for the use of compensated panels, educators, or other resources that center the voices of transgender students: compensate those within the transgender community who are willing to spend time and energy on creating educational resources, and rely on the knowledge of those who have already made such information available, rather than extracting such labor from students who have not volunteered it. Additionally, the author of the present study would suggest that faculty be proactive and self-directed in their efforts toward allyship, and avoid reliance on ignorance as an excuse for inaction or lack of appropriate advocacy. Findings may also be used to facilitate dialogue between students and professors regarding the ways that marginalized student populations, both within and outside of the transgender community, can be best served. 


\section{Conclusion}

While transgender students are often met with prejudice or otherwise overlooked in university settings, the present study seeks to provide a vehicle through which their stories can inform better practices at Portland State University and other similar institutions. The present study may also serve to inform the development of transgender-specific classroom resources for faculty that help address common prejudice-based behaviors. This will hopefully help educators to better facilitate positive learning experiences for transgender students in their classrooms, and to foster positive relationships between transgender students and educators more broadly. Findings may also help to inform other professionals working with transgender students (e.g. campus resources for LGBT+ students, mental health, academic success) by increasing understanding of transgender experiences and the barriers this population faces within academic institutions. Moving forward, it is intended that the perspectives and changes outlined above will be used to develop classroom programming that may ultimately improve not only the classroom experience for transgender students, but the attitudes of all students toward transgender individuals. 


\section{References}

Austin, A. (2016). “There I am”: A Grounded Theory study of young adults navigating a transgender or gender nonconforming identity within a context of oppression and invisibility. Sex Roles, 1-16.

Chang, T. K., \& Chung, Y. B. (2015). Transgender microaggressions: Complexity of the heterogeneity of transgender identities. Journal of LGBT Issues in Counseling, 9(3), 217-234.

Chang, S. C., Singh, A. A., \& Rossman, K. (2017). Gender and sexual orientation diversity within the TGNC community.

Davidson, M. R. (2014). Development and validation of the transgender prejudice scale.

Garvey, J. C., \& Rankin, S. R. (2015). The influence of campus experiences on the level of outness among trans-spectrum and queer-spectrum students. Journal of Homosexuality, $62,374-393$.

James, S. E., Herman, J. L., Rankin, S., Keisling, M., Mottet, L., \& Anafi, M. (2016). The Report of the 2015 U.S. Transgender Survey. Washington, DC: National Center for Transgender Equality.

Moran, L. J., \& Sharpe, A. N. (2004). Violence, identity and policing: The case of violence against transgender people. Criminal Justice, 4(4), 395-417.

Nadal, K. L., Rivera, D. P., \& Corpus, J. H. (2010). Sexual orientation and transgender microaggressions. Microaggressions and marginality: Manifestation, dynamics, and impact, 217-240. 
Nadal, K. L., Skolnik, A., \& Wong, Y. (2012). Interpersonal and systemic microaggressions toward transgender people: Implications for counseling. Journal of LGBT Issues in Counseling, 6(1), 55-82.

Palkki, J. (2017). Inclusivity in action: Transgender students in the choral classroom. Choral Journal, 57(11), 20-34.

Pryor, J. T. (2015). Out in the classroom: Transgender student experiences at a large public university. Journal of College Student Development, 56(5), 440-455.

Renn, K. A. (2010). LGBT and queer research in higher education: The state and status of the field. Educational Researcher, 8, 132-141.

Sue, D. W., Capodilupo, C. M., Torino, G. C., Bucceri, J. M., Holder, A., Nadal, K. L., \& Esquilin, M. (2007). Racial microaggressions in everyday life: Implications for clinical practice. American Psychologist, 62(4), 271. 